\title{
Allogeneic Hematopoietic Cell Transplantation and Cellular Therapy
}

\author{
Hee-Je Kim', Daniel Weisdorf², David J Gottlieb
}

${ }^{1}$ Catholic Hematology Hospital, Seoul St. Mary's Hospital, College of Medicine, The Catholic University of Korea, Seoul, the Republic of Korea, ${ }^{2}$ Division of Hematology, Oncology and Transplantation, University of Minnesota, Minneapolis, U.S.A, ${ }^{3}$ Westmead Hospital University of Sydney, Sydney, Australia

\begin{abstract}
Patients with acute myeloid leukemia (AML) and myelodysplastic syndrome (MDS) generally require allogeneic hematopoietic cell transplantation (allo-HCT) for a cure, except for patients with favorable genetic genotypes such as those with core-binding factor AML. However, the use of intensive chemotherapy followed by prompt HCT does not fully prevent relapse or refractory disease. Despite improvements in transplant techniques and management of complications, further improvement of HCT outcomes is urgently needed. Moreover, careful patient counseling, donor selection, and choice of transplant type are essential to maximize the benefits of early allografting. Maintenance after HCT focusing on selective immunomodulation combined with targeted immunotherapies that control persisting or relapsed hematologic malignancies is currently under active investigation. To improve the balance between GVHD, relapse, and infection, the use of purified blood stem cell grafts in conjunction with ex vivo expanded T-cells from stem cell donors targeting common infectious and leukemic antigens has been explored. T cells against infectious agents might also be generated using partially HLA-matched thirdparty $T$ cells from cryopreserved cell banks, and a series of studies confirmed the clinical value of donor-derived CMV- and EBV-specific T cells. This approach has also been applied to acute leukemia, and trials using donorderived cytotoxic T-cells targeting multiple leukemic antigens such as WTI, PRAME, survivin, and NY-ESO, as well as donor-derived CAR19 T-cells after allo-HCT, are currently underway.
\end{abstract}

Key words hematopoietic cell transplantation, AML, MRD, GVHD, cytotoxic T-cell, CAR T-cell

Submitted August 16, 2021; Accepted August 31, 2021; Published online October 14, 2021; Issued online October 14, 2021

Correspondence: Hee-Je Kim, Catholic Hematology Hospital, Seoul St. Mary's Hospital, College of Medicine, The Catholic University of Korea, 222 Banpo-daero, Seocho-gu, 06591, Seoul, South Korea, E-mail: cumckim@catholic.ac.kr

This article was created from selected presentations at the 26th Annual Congress of APBMT and was handled by Guest Editor Shinichiro Okamoto before submission.

\section{Introduction}

Patients with acute myeloid leukemia (AML) not in complete remission $(\mathrm{CR})$ or myelodysplastic syndrome (MDS) have few therapeutic options, and most require allo-HCT for cure ${ }^{1-5}$. The decision of when, how and whether to transplant requires consideration of alternatives and potential loss of curative option if nontransplant therapy proceeds. Patients' personal willingness to accept risks, leukemia phenotype, and available transplant options influence the decision and timing of transplantation.

Additionally, there is no established post-HCT main- tenance therapy for hematologic malignancies, especially for acute leukemia. We have attempted to separate GVL from GVHD with limited success. We need more potent and specific tools combined with novel drugs, small molecules, and advanced immunomodulating techniques, including genetically engineered cells or vaccines, to eradicate chemo-resistant leukemic cells and limit post-transplant relapse.

In this review, we summarize the current status of patient selection and optimal timing for HCT and recent advances in post-transplantation therapy to improve outcomes of HCT. 


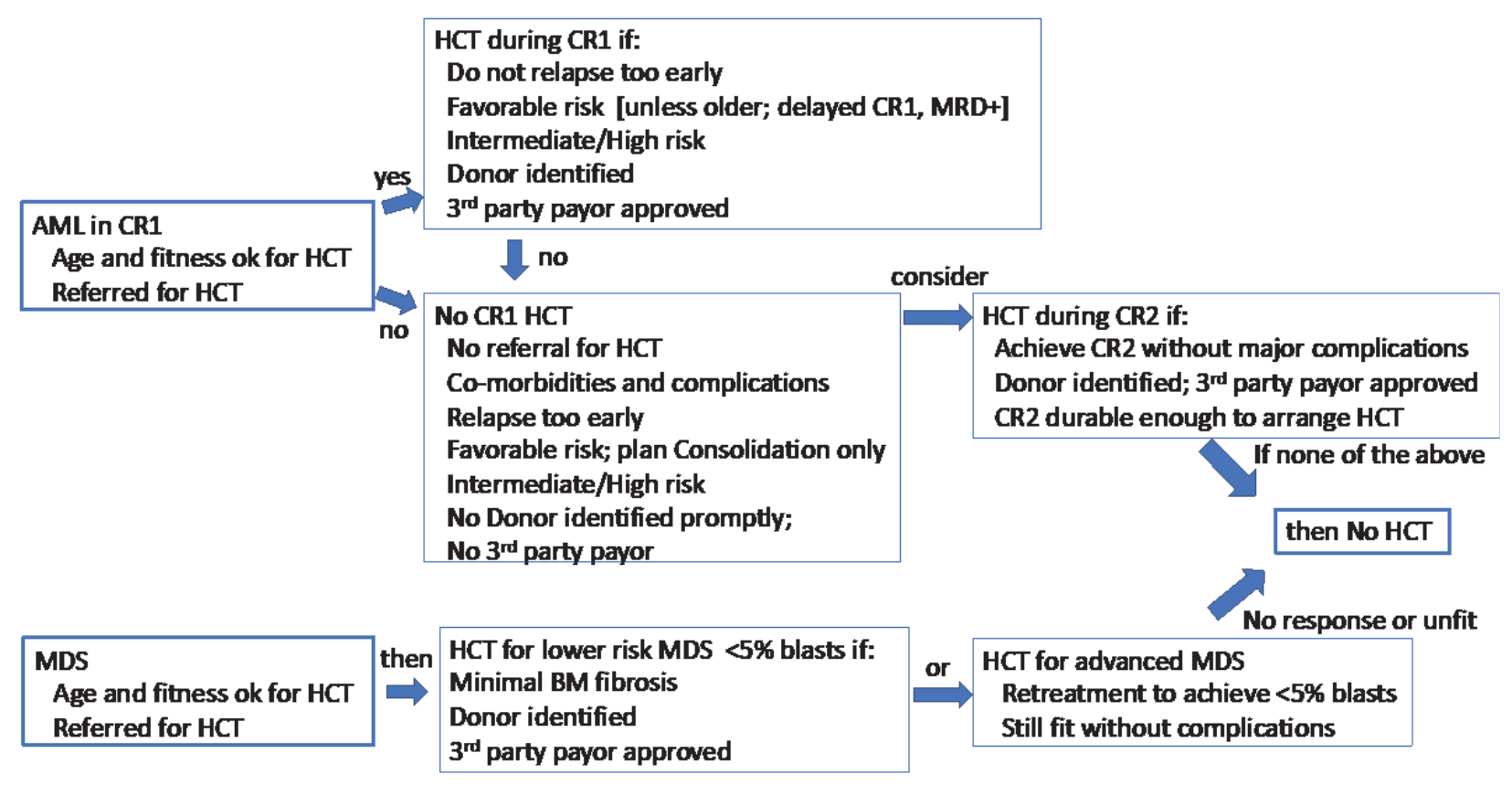

Figure 1. Outlining the Timing and Decision-Making factors influencing Allo-HCT for AML and MDS

\section{Anti-leukemic Maintenance Therapies after Allo- HCT in Adult Patients with AML}

The concept of maintenance therapy after either alloHCT or autologous hematopoietic cell transplantation (auto-HCT) mainly focused on selective immunomodulation using niche-refreshing agents, such as azacitidine and CXCR4 inhibitors combined with specific- or nonspecific conventional immunotherapies, as a major promising part of treatment against primary chemoresistant refractory or relapsed high-risk acute leukemias. Wilms' tumor gene 1 (WT1) is a marker of nonspecific leukemia-associated antigen (LAA) to monitor the minimal residual disease (MRD) status during and after treatment of AML or as a target for anti-leukemic therapy in patients with $\mathrm{AML}^{6-9}$.

Adoptive immunotherapies using stratified WT1specific vaccine, WT1-specific CTLs, CART/NK cells, bispecific killer cell engager $\mathrm{T}$ cells, gene transferred mesenchymal stromal cells (MSCs), and the combination of various immunomodulating novel agents or well-designed sequential approaches have been introduced. These adoptive immunotherapies should be applied to many high-risk patients with acute leukemias in need of treatment and to prevent relapse $\mathrm{e}^{10-14}$.

Many trials have shown that allo-HCT could compensate for the negative prognostic impact of the FLT3ITD mutation. In a subgroup of patients with FLT3 mutated AML, a series of tyrosine kinase inhibitors (TKIs), such as gilteritinib, are currently being investigated to clarify their efficacy in preventing posttransplant relapse. These trials must shed light to enrich the benefits of TKIs post-HCT in very high-risk patients with AML. However, further investigations are warranted to develop a more potent and precise strategy as a post-transplant maintenance therapy combined with various novel drugs, small molecules, or advanced immunomodulating techniques and cells, especially vaccines.

In this short report, we introduce the background and clinical outcomes of our anti-leukemic CTL therapy to understand the mechanisms of anti-leukemic T-cell immunity in adult patients with AML and WT1 expression, as a foundation and a next step developmental strategy for conventional adoptive cellular therapy, which can be effectively utilized in therapeutic and preventive settings in refractory and relapse-prone patients with AML. Based on our previous reports of sustained clinical remission achieved by $\mathrm{T}$ cell responses after infusing the in vitro cultured WTI-specific T cells, which were expanded in vivo to elicit long-lasting antileukemic immunity in allo-HCT settings, it should still be one of the good ways of applying personalized care in patients with high-risk AML in real clinical settings ${ }^{15}$.

A patient was diagnosed with high-risk secondary AML transformed from myelodysplastic syndrome (RAEB-2) in 2005 and received two cycles of consecutive induction chemotherapies, but failed to achieve CR. He subsequently underwent the first allo-HCT from his sibling donor, but leukemia relapsed 10 months later without any acute or chronic graft-versus-host disease (GvHD). He received further salvage chemotherapy with FLAG-Ida followed by donor lymphocyte infusion 
and achieved complete remission approximately 2-3 weeks after the completion of the above therapies. Then, four consecutive doses of WT1-CTLs $(2 \times$ $10^{7} / \mathrm{m}^{2}$ ) with a 3-week interval were intravenously infused without any immediate and delayed toxicity, but severe acute hepatitis developed after the initial two doses of IL-2. After completion of CTL therapy, the patient developed an overlap syndrome at the skin, mouth, and eyes. The patient remained free of AML for 37 months after $W T 1$-specific CTL immunotherapy. Unfortunately, AML relapsed in November 2008, and the patient died 2 months later ${ }^{15}$.

By monitoring the kinetics of infused truncated WTICTLs, we found that $W T 1$-specific IFN- $\gamma$-secreting T cells in the peripheral blood increased progressively during serial infusion of WTI-CTLs and the pattern persisted until 9 months, and specific T-cell responses against $W T 1$ were maintained until the last examination at 2 years when $W T 1$-specific IFN-gamma-secreting T cells were detected in both CD4+ and CD8+ T cells. IFN- $\gamma$-secreting CD8+ T cells specific for WT1-187 and WT1-235 were more frequently observed than those for WT1-126. These results were similar to the specificity of the generated CTLs, suggesting that $W T 1$-specific T cells might have been derived from infused CTLs and had been maintained. Despite some limitations, this pilot study has several important clinical implications. This trial using a truncated gene was a new approach to trace transferred cells in a clinical setting ${ }^{15}$.

A total of 13 newly diagnosed adult patients treated for AML between 2007 and 2008 in the Catholic Hematology Hospital (former Catholic Blood and Marrow Transplantation Center) were considered eligible for a prospective phase I/II study with very long-term followup if they had a human leukocyte antigen (HLA)identical sibling donor. Despite the small number of patients enrolled in this refined prospective study, the exploratory trial of WT1-CTLs after allo-HCT for highrisk AML suggested that this well-coordinated therapeutic strategy may be used combined with elective allo- or even auto-HCT with WTI-CTL infusion. The generation of multi-antigen-specific T-cells that enhance the graftversus-leukemia effect and prevent infection after alloHCT, as well as the development of immunotherapy using T-cell receptor (TCR)-engineered T-cells, may be a promising treatment in the near future ${ }^{16}$.

Furthermore, our group found that most adult patients with AML expressed at least one leukemiaassociated antigen WT1, survivin, and TERT, as well as different combinations of the three LAAs that predicted poor clinical outcomes ${ }^{17}$. Adopting monovalent WT1specific CTL therapy performed in a pilot trial more than a decade ago provided positive results ${ }^{10,}{ }^{11}$; therefore, we designed multi-tumor antigen-specific T-cells to maximize anti-leukemic effects in patients with highrisk $\mathrm{AML}^{12}$. To generate three antigen-specific T-cells that recognize three LAAs, dendritic cells were transfected with three AML antigen-encoding RNAs. These DCs were used to stimulate CD8 and CD4 T cells and overcome the limitations of known HLA-restricted epitopes.

The three antigen-specific T-cells were more effective against leukemic blasts that expressed all three LAAs compared to those that expressed one or two LAAs. Engrafted leukemic blasts in the bone marrow of NSG mice significantly decreased in the presence of three antigen-specific T-cells. This technique is an effective immunotherapeutic strategy for AML. We are planning to further a phase $1 / 2$ trial to evaluate tri-T cells against high-risk MRD-positive patients with adult AML in the near future ${ }^{18}$.

\section{Timing of Allogeneic Hematopoietic Cell Trans- plantation (Allo-HCT): the Knowns and the Known Unknowns}

Treatment timing has a substantial impact on the success of allo-HCT (Figure 1). While it is generally recognized that overall survival (OS) after HCT is best if performed during CR1, those with a long initial remission and late (beyond 1.5-2 years) relapse may have similarly favorable post-HCT OS, even if performed during this late CR2 $2^{19-24}$. This is partly because those with a higher risk of relapse are excluded from reports of CR2 HCT. Some patients who relapsed from CR1 failed to achieve CR2, while others accumulated complications during reinduction that precluded the option of HCT in CR2. Those receiving CR2 HCT were in neither of those higher risk and excluded cohorts.

Conversely, the time to HCT when performed in CR1 reflects an indirect selection bias. In most series, the median time to AML CR1 HCT is $>6$ months, thus reflecting either exclusion of those with early relapse or whose HCT could not be arranged and initiated more promptly. A longer time to HCT in CR1 generally results in better survival, reflecting this indirect but generally not quantified or reported selection bias.

Patient age, comorbidities, and complications acquired during induction directly influence the risk of non-relapse mortality (NRM) ${ }^{25}$. Organ dysfunction, infections, nutrition, and frailty measures summed into either performance status or detailed in the HCTcomorbidity index (-CI) have been reported to predict HCT outcomes, particularly NRM. Whether these influences are quantitatively similar across donor types and following ablative vs. reduced-intensity conditioning is uncertain.

The leukemia phenotype directly influences the risk 
of relapse, and difficulty or delay in achieving CR requiring additional induction treatments can also compromise fitness for $\mathrm{HCT}^{29-28}$. If transplantation is deferred for those in CR1, 20-40\% of those with favorable molecular and cytogenetic risk can still face early progression with a median time to relapse of $\sim 12$ months. Intermediate and high-risk features generally favor early transplantation because CR1 can be brief, and relapse is nearly always expected. However, even for AML in CR1, a greater number of chemotherapy cycles to achieve CR1 and measurable residual disease (MRD) pre-HCT compromises the likelihood of HCT success, both from NRM and higher risks of post-HCT relapse ${ }^{29-38}$. MDS patients have no alternative curative option despite the benefits of hypomethylating agents or other treatments. Progression beyond early-stage MDS greatly limits HCT success, mostly by augmenting relapse risks. IPSS-R beyond low- and intermediate-risk or WHO subgroups with excess blasts have poor survival without HCT, especially for those $>60$ years old.

If the choice favors HCT, a suitable and promptly available allogeneic donor is essential. Donor searching, therefore, should be initiated soon after diagnosis to facilitate donor identification and testing. While HLAmatched siblings and unrelated donor (URD) HCT are the standard first choice and yield similar HCT success, the time required for URD identification and graft arrangements can, even without unplanned delays, compromise those needing an urgent transplant, and are sometimes confounded by leukemia recurrence while awaiting an HCT that was planned for CR $1^{39-44}$. Haploidentical, related donor grafts (who can be parents, siblings, or children) have been revolutionized by postHCT cyclophosphamide as GVHD prophylaxis. Haploidentical grafts are immediately available, although the completeness of immune constitution, the hazards of infection, and risks of relapse remain uncertain. Umbilical cord blood (UCB), another graft that can overcome HLA disparity and thus serve ethnic and racial minorities, is limited by greater risks of graft failure and consequent NRM.

All these factors need to be discussed with patients to assess their willingness to assume risks in the hope of better outcomes. Older patients, even after successful induction therapy, may be debilitated or fatigued ${ }^{45-52}$. They may be unwilling to assume greater risks and accept the unknowns that accompany the decision for transplantation during CR1. While recent data support the survival advantage of HCT during CR1 for older patients with AML, it reflects the yield of patient and care team discussions balancing the risks and potential benefits of this aggressive approach. Thoughtful patient selection may inflate these benefits for those who have chosen HCT; however, results for older AML and MDS patients without HCT are disappointing. Thus, early donor searching, patient education about available options, and willingness to offer HCT for fit patients even in their 70s may increase those who elect this potentially curative option. Careful patient counseling along with risk-adapted and intensive supportive care is essential to minimize the hazards and maximize the benefit of early allografting for all high-risk illnesses. Withholding the decision-making option from patients yields selffulfilling and expectedly poor outcomes.

\section{Combining Infection and Malignancy Targeted T- cell Therapy with Stem Cell Isolation for a New Paradigm in Allo-HCT}

Infection, GVHD, and relapse of malignancy remain the most difficult complications associated with allogeneic HCT. Over more than 50 years, the separation of GVHD and post-transplant relapse has been the holy grail of transplant but has remained elusive. Treatment of either complication promotes development of the other, and treatment of both results in increased infection. Infection is the most common contributor to NRM, the largest cause of death in the first year following allograft. Disease relapse is the dominant cause of death beyond 1 year after allo-HCT ${ }^{53}$.

The early discovery that cloned T-cells could reconstitute cytomegalovirus immunity after transplantation was followed by seminal work by Brenner, Rooney, and Heslop, showing that ex vivo expanded Epstein-Barr virus (EBV)-specific T-cells manufactured from stem cell donors were not only free from complications, but were extremely effective both in the treatment and prophylaxis of EBV-driven diseases ${ }^{54}$. Their work focused on post-transplant lymphoproliferative disease and was followed by investigation of CMV-specific T-cells in patients with refractory CMV disease, particularly pneumonitis, where very encouraging rates of response were observed $^{55}$.

$\mathrm{T}$ cell therapies were largely considered valuable additions to a relatively restricted therapeutic armamentarium against diseases caused by CMV and EBV. The idea was that they would be called upon when standard therapies failed due to lack of efficacy or intolerance. The concept of using T-cells for rapid reconstitution of broad immunity, though inherent in early EBV prophylaxis studies, grew with the observation that CMVspecific T-cells administered prophylactically reduced the peak of viremia and the requirement for CMV antiviral therapy ${ }^{56}$. In addition, there was a growing realization that $\mathrm{T}$ cells could be manufactured with specificity for a wider range of viral infections (including adenovirus, BK virus, influenza, HHV-6, varicella, and JC virus), and that $\mathrm{T}$ cells play a key role in antifungal im- 
munity $^{57-60}$. The latter could also be expanded ex vivo ${ }^{61}$. These findings suggest that infusion of broadly reactive T-cells might rapidly recreate immune competence after immune-ablative therapy such as $\mathrm{HCT}^{62}$.

Despite this, several logistic issues continue to stand in the way of a broad introduction of this approach to allo-HCT. The cost and complexity of manufacturing remained as obstructions, and the use of the stem cell donor as a source of anti-viral/fungal T-cells meant that the approach remained highly personalized. With long cell manufacturing times, there was little interest in providing complex and expensive services. Facilities and expertise were insufficient for such an approach to be widely implemented. However, improvements in manufacturing techniques, including shortening of the culture period from 7 to 10 days and the use of gas-permeable culture vessels have resulted in reassessment of personalized cell therapy ${ }^{63}$.

Furthermore, the introduction of genetically modified chimeric antigen receptor (CAR)-bearing T-cell therapy has resulted in a thorough assessment of issues such as T-cell fitness, standardization of apheresis, product chain of custody, and cold chain supply. Once thought insurmountable, these challenges have been successfully addressed, albeit at some expense. The result has been broad acknowledgement of the logistic ability to introduce cellular therapies into routine clinical care and their acceptance by hematologists and transplant physicians with little prior experience in the field of cell therapies.

In contrast, the creation of individual T-cell products for all or the majority of stem cell transplant recipients remains a daunting prospect for routine transplant programs with no experience in cell manufacture. An important advance that might wholly or partially circumvent this problem was the recognition that T-cells from third-party donors (that is neither the patient nor the stem cell donor) can mediate important therapeutic benefits even when not fully HLA matched with the patient $^{64,65}$. However, some important differences exist between the use of donor-derived and third-party T-cell products.

Donor-derived T-cells persist for years after infusion, expanding, and contracting according to the antigen load, thus providing long-term immune competence. In contrast, most studies suggest that partially HLAmatched $\mathrm{T}$ cells persist for periods of weeks to a few months only, and even then, at very low levels, at least in the blood. The mechanism of their effects is unclear. Moreover, short- and long-term studies have demonstrated virological response rates of approximately 75\% and over $90 \%$ for CMV, EBV, and adenovirus infections treated with partially HLA-matched T-cells. Because of the need for only partial HLA matching with the recipient, a relatively small bank of T-cell products (15-20 in total) is sufficient to cover more than 95\% of infections in transplant patients if donors with HLA molecules common in the transplant cohort are selected for creation of bank products ${ }^{66}$.

Multiple methods for the reduction of GVHD after allogeneic HCT have been proposed, including CD34 stem cell selection or its variants such as CD3/CD19 depletion or $\alpha \beta / C D 19$ depletion, photodepletion of alloreactive donor $\mathrm{T}$ cells, and naïve $\mathrm{T}$ cell depletion. All such maneuvers can be combined with post-transplant addition of $\mathrm{T}$ cells targeting specific infections and malignancy. $T$ cells targeting leukemia include those stimulated with peptides from tumor antigens such as WT-1, PRAME, survivin, NY-ESO, and MAGE proteins, but also potentially include the use of genetically modified $\mathrm{T}$ cells expressing either transgenic or CARs recognizing tumor antigens appropriate to the patient's disease $^{7,8,67}$. The uncoupling of GVHD and disease relapse will rely on the removal of non-specific donor immune responses against major and minor HLA antigens expressed by the recipient and their replacement with known and desired immune responses to pathogens and tumor antigens that have little or no pathogenic effect on the recipient. Such trials are already in existence, and early results bode well for a fundamental change in the approach to allo-HCT.

\section{Conclusion}

Consideration of the best treatment for high-risk patients with acute leukemia and their suitability as candidates for allo-HCT requires careful attention through the process of early donor searching, patient education about the options and willingness to accept risk, and careful selection of transplant options. This is especially true in older patients. Careful patient counseling along with risk-adapted and intensive supportive care is essential to minimize hazards and maximize the benefit of early allografting for those with high-risk parameters. Although serious infections, high-grade acute and chronic GVHD, and relapse of underlying malignancy remain the most challenging complications after alloHCT, the uncoupling of GVHD and disease relapse with reduction of non-specific donor immune responses against recipient HLA antigens and focused immune responses directed towards pathogens and tumor antigens is developing, and early results are promising. AlloHCT may become safer and more available to a broader patient population still needing better options for ongoing leukemia management. 


\section{Author Contributions}

HJK, DW, and DJG conceived and wrote the article.

\section{Conflict of interest}

The authors declare no conflicts of interest associated with this article. Disclosure forms provided by the authors are available on the website.

Hee-Je Kim is one of the Editors of Blood Cell Therapy. He was not involved in the editorial evaluation or decision to accept this article for publication.

\section{References}

1. Koreth J, Schlenk R, Kopecky KJ, Honda S, Sierra J, Djulbegovic BJ, et al. Allogeneic stem cell transplantation for acute myeloid leukemia in first complete remission: systematic review and meta-analysis of prospective clinical trials. JAMA. 2009; 301: 2349-61.

2. Dohner H, Estey E, Grimwade D, Amadori S, Appelbaum FR, Buchner T, et al. Diagnosis and management of AML in adults: 2017 ELN recommendations from an international expert panel. Blood. 2017; 129: 424-47.

3. Tallman MS, Wang ES, Altman JK, Appelbaum FR, Bhatt VR, Bixby D, et al. Acute Myeloid Leukemia, Version 3.2019, NCCN Clinical Practice Guidelines in Oncology. J Natl Compr Canc Netw. 2019; 17: 721-49.

4. Dohner H, Weisdorf DJ, Bloomfield CD. Acute Myeloid Leukemia. N Engl J Med. 2015; 373: 1136-52.

5. Cornelissen JJ, Versluis J, Passweg JR, van Putten WL, Manz MG, Maertens J, et al. Comparative therapeutic value of postremission approaches in patients with acute myeloid leukemia aged 40-60 years. Leukemia. 2015; 29: 1041-50.

6. Cho BS, Min GJ, Park SS, Shin SH, Yahng SA, Jeon YW, et al. WT1 Measurable Residual Disease Assay in Patients With Acute Myeloid Leukemia Who Underwent Allogeneic Hematopoietic Stem Cell Transplantation: Optimal Time Points, Thresholds, and Candidates. Biol Blood Marrow Transplant. 2019; 25: 1925-32.

7. Park S, Min GJ, Park SS, Yahng SA, Jeon YW, Shin SH, et al. Comparison of Myeloablative (CyTBI, BuCy) versus Reduced-Intensity (FluBu2TBI400) Peripheral Blood Stem Cell Transplantation in Acute Myeloid Leukemia Patients with Pretransplant Low WT1 Expression. Biol Blood Marrow Transplant. 2020; 26: 2018-26.

8. Yoon JH, Kim HJ, Jeon YW, Lee SE, Cho BS, Eom KS, et al. Outcome of allogeneic hematopoietic stem cell transplantation for cytogenetically normal AML and identification of high-risk subgroup using WT1 expression in association with NPM1 and FLT3-ITD mutations. Genes Chromosomes Cancer. 2015 ; 54: 489-99.

9. Yoon JH, Kim HJ, Kwak DH, Park SS, Jeon YW, Lee SE, et al. High WT1 expression is an early predictor for relapse in patients with acute promyelocytic leukemia in first remission with negative PML-RARa after anthracycline-based chemotherapy: a single-center cohort study. J Hematol Oncol. 2017; 10: 30 .

10. Uttenthal B, Martinez-Davila I, Ivey A, Craddock C, Chen F,
Virchis A, et al. Wilms' Tumour 1 (WT1) peptide vaccination in patients with acute myeloid leukaemia induces short-lived WT1-specific immune responses. Br J Haematol. 2014; 164: 366-75.

11. Candoni A, De Marchi F, Zanini F, Zannier ME, Simeone E, Toffoletti E, et al. Predictive value of pretransplantation molecular minimal residual disease assessment by WT1 gene expression in FLT3-positive acute myeloid leukemia. Exp Hematol. 2017; 49:25-33.

12. Chapuis AG, Egan DN, Bar M, Schmitt TM, McAfee MS, Paulson KG, et al. T cell receptor gene therapy targeting WT 1 prevents acute myeloid leukemia relapse post-transplant. Nat Med. 2019; 25: 1064-72.

13. Lulla PD, Naik S, Vasileiou S, Tzannou I, Watanabe A, Kuvalekar $\mathrm{M}$, et al. Clinical effects of administering leukemiaspecific donor $\mathrm{T}$ cells to patients with AML/MDS after allogeneic transplant. Blood. 2021; 137: 2585-97.

14. Inoue $\mathrm{K}$, Sugiyama $\mathrm{H}$, Ogawa $\mathrm{H}$, Nakagawa $\mathrm{M}$, Yamagami $\mathrm{T}$, Miwa $\mathrm{H}$, et al. WT1 as a new prognostic factor and a new marker for the detection of minimal residual disease in acute leukemia. Blood. 1994; 84: 3071-9.

15. Kim YJ, Cho SG, Lee S, Kim MS, Kim EK, Cho BS, et al. Potential role of adoptively transferred allogeneic WT1specific CD4+ and CD8+ T lymphocytes for the sustained remission of refractory AML. Bone Marrow Transplant. 2010; 45: $597-9$.

16. Kim HJ, Sohn HJ, Hong JA, Lee HJ, Sohn DH, Shin CA, et al. Post-transplant immunotherapy with WT1-specific CTLs for high-risk acute myelogenous leukemia: a prospective clinical phase I/II trial. Bone Marrow Transplant. 2019; 54: 903-6.

17. Kim HJ, Choi EJ, Sohn HJ, Park SH, Min WS, Kim TG. Combinatorial molecular marker assays of WT1, survivin, and TERT at initial diagnosis of adult acute myeloid leukemia. Eur J Haematol. 2013; 91: 411-22.

18. Sohn HJ, Lee JY, Lee HJ, Sohn DH, Cho HI, Kim HJ, et al. Simultaneous in vitro generation of CD8 and CD4 T cells specific to three universal tumor associated antigens of WT1, survivin and TERT and adoptive $\mathrm{T}$ cell transfer for the treatment of acute myeloid leukemia. Oncotarget. 2017; 8: 4405972.

19. Kharfan-Dabaja MA, Labopin M, Bazarbachi A, Socie G, Kroeger N, Blaise D, et al. Higher busulfan dose intensity appears to improve leukemia-free and overall survival in AML allografted in CR2: An analysis from the Acute Leukemia Working Party of the European Group for Blood and Marrow Transplantation. Leuk Res. 2015; 39: 933-7.

20. Michelis FV, Messner HA, Atenafu EG, McGillis L, Lambie A, Uhm J, et al. Patient age, remission status and HCT-CI in a combined score are prognostic for patients with AML undergoing allogeneic hematopoietic cell transplantation in CR1 and CR2. Bone Marrow Transplant. 2015; 50: 1405-10.

21. Michelis FV, Gupta V, Zhang MJ, Wang HL, Aljurf M, Bacher U, et al. Cytogenetic risk determines outcomes after allogeneic transplantation in older patients with acute myeloid leukemia in their second complete remission: A Center for International Blood and Marrow Transplant Research cohort analysis. Cancer. 2017; 123: 2035-42.

22. Hospital MA, Prebet T, Bertoli S, Thomas X, Tavernier E, Braun $\mathrm{T}$, et al. Core-binding factor acute myeloid leukemia in first relapse: a retrospective study from the French AML In- 
tergroup. Blood. 2014; 124: 1312-9.

23. Weisdorf DJ, Millard HR, Horowitz MM, Hyare PS, Champlin R, Ho V, et al. Allogeneic transplantation for advanced acute myeloid leukemia: The value of complete remission. Cancer. 2017; 123: 2025-34.

24. Gilleece MH, Labopin M, Savani BN, Yakoub-Agha I, Socie G, Gedde-Dahl T, et al. Allogeneic haemopoietic transplantation for acute myeloid leukaemia in second complete remission: a registry report by the Acute Leukaemia Working Party of the EBMT. Leukemia. 2020; 34: 87-99.

25. Bejanyan N, Zhang M, Bo-Subait K, Brunstein C, Wang H, Warlick ED, et al. Myeloablative Conditioning for Allogeneic Transplantation Results in Superior Disease-Free Survival for Acute Myelogenous Leukemia and Myelodysplastic Syndromes with Low/Intermediate but not High Disease Risk Index: A Center for International Blood and Marrow Transplant Research Study. Transplant Cell Ther. 2021; 27: 68 e1-9.

26. Han SY, Mrozek K, Voutsinas J, Wu Q, Morgan EA, Vestergaard $\mathrm{H}$, et al. Secondary cytogenetic abnormalities in corebinding factor AML harboring inv(16) vs $\mathrm{t}(8 ; 21)$. Blood Adv. 2021; 5: 2481-9.

27. Schlenk RF, Pasquini MC, Perez WS, Zhang MJ, Krauter J, Antin JH, et al. HLA-identical sibling allogeneic transplants versus chemotherapy in acute myelogenous leukemia with $t$ $(8 ; 21)$ in first complete remission: collaborative study between the German AML Intergroup and CIBMTR. Biol Blood Marrow Transplant. 2008; 14: 187-96.

28. Lv M, Wang Y, Chang YJ, Zhang XH, Xu LP, Jiang Q, et al. Myeloablative Haploidentical Transplantation Is Superior to Chemotherapy for Patients with Intermediate-risk Acute Myelogenous Leukemia in First Complete Remission. Clin Cancer Res. 2019; 25: 1737-48.

29. Buccisano F, Maurillo L, Spagnoli A, Del Principe MI, Fraboni D, Panetta P, et al. Cytogenetic and molecular diagnostic characterization combined to postconsolidation minimal residual disease assessment by flow cytometry improves risk stratification in adult acute myeloid leukemia. Blood. 2010; 116: 2295-303.

30. Freeman SD, Hills RK, Virgo P, Khan N, Couzens S, Dillon $\mathrm{R}$, et al. Measurable Residual Disease at Induction Redefines Partial Response in Acute Myeloid Leukemia and Stratifies Outcomes in Patients at Standard Risk Without NPM1 Mutations. J Clin Oncol. 2018; 36: 1486-97.

31. Hemmati PG, Terwey TH, Na IK, le Coutre P, Jehn CF, Vuong LG, et al. Impact of early remission by induction therapy on allogeneic stem cell transplantation for acute myeloid leukemia with an intermediate-risk karyotype in first complete remission. Eur J Haematol. 2015; 94: 431-8.

32. Hourigan CS, Dillon LW, Gui G, Logan BR, Fei M, Ghannam J, et al. Impact of Conditioning Intensity of Allogeneic Transplantation for Acute Myeloid Leukemia With Genomic Evidence of Residual Disease. J Clin Oncol. 2020; 38: 127383.

33. Mawad R, Gooley TA, Sandhu V, Lionberger J, Scott B, Sandmaier BM, et al. Frequency of allogeneic hematopoietic cell transplantation among patients with high- or intermediate-risk acute myeloid leukemia in first complete remission. J Clin Oncol. 2013; 31: 3883-8.

34. Schuurhuis GJ, Heuser M, Freeman S, Bene MC, Buccisano $\mathrm{F}$, Cloos $\mathrm{J}$, et al. Minimal/measurable residual disease in AML: a consensus document from the European Leukemi-
aNet MRD Working Party. Blood. 2018; 131: 1275-91.

35. Short NJ, Zhou S, Fu C, Berry DA, Walter RB, Freeman SD, et al. Association of Measurable Residual Disease With Survival Outcomes in Patients With Acute Myeloid Leukemia: A Systematic Review and Meta-analysis. JAMA Oncol. 2020; 6: 1890-9.

36. Venditti A, Piciocchi A, Candoni A, Melillo L, Calafiore V, Cairoli R, et al. GIMEMA AML1310 trial of risk-adapted, MRD-directed therapy for young adults with newly diagnosed acute myeloid leukemia. Blood. 2019; 134: 935-45.

37. Walter RB, Gyurkocza B, Storer BE, Godwin CD, Pagel JM, Buckley SA, et al. Comparison of minimal residual disease as outcome predictor for AML patients in first complete remission undergoing myeloablative or nonmyeloablative allogeneic hematopoietic cell transplantation. Leukemia. 2015; 29: 137-44.

38. Yu S, Fan Z, Ma L, Wang Y, Huang F, Zhang Q, et al. Association Between Measurable Residual Disease in Patients With Intermediate-Risk Acute Myeloid Leukemia and First Remission, Treatment, and Outcomes. JAMA Netw Open. 2021; 4: e2115991.

39. Bashey A, Zhang X, Sizemore CA, Manion K, Brown S, Holland HK, et al. T-cell-replete HLA-haploidentical hematopoietic transplantation for hematologic malignancies using post-transplantation cyclophosphamide results in outcomes equivalent to those of contemporaneous HLA-matched related and unrelated donor transplantation. J Clin Oncol. 2013; 31: 1310-6.

40. Peffault de Latour R, Brunstein CG, Porcher R, Chevallier P, Robin M, Warlick E, et al. Similar overall survival using sibling, unrelated donor, and cord blood grafts after reducedintensity conditioning for older patients with acute myelogenous leukemia. Biol Blood Marrow Transplant. 2013; 19: 1355-60.

41. Piemontese S, Boumendil A, Labopin M, Schmid C, Ciceri F, Arcese W, et al. Leukemia relapse following unmanipulated haploidentical transplantation: a risk factor analysis on behalf of the ALWP of the EBMT. J Hematol Oncol. 2019; 12: 68.

42. Ustun C, Giannotti F, Zhang MJ, Wang HL, Brunstein C, Labopin M, et al. Outcomes of UCB transplantation are comparable in FLT3+ AML: results of CIBMTR, EUROCORD and EBMT collaborative analysis. Leukemia. 2017; 31: 140814.

43. Wang Y, Liu QF, Xu LP, Liu KY, Zhang XH, Ma X, et al. Haploidentical vs identical-sibling transplant for AML in remission: a multicenter, prospective study. Blood. 2015; 125: 3956-62.

44. Yu S, Huang F, Wang Y, Xu Y, Yang T, Fan Z, et al. Haploidentical transplantation might have superior graft-versusleukemia effect than HLA-matched sibling transplantation for high-risk acute myeloid leukemia in first complete remission: a prospective multicentre cohort study. Leukemia. 2020; 34: 1433-43.

45. Juliusson G, Antunovic P, Derolf A, Lehmann S, Mollgard L, Stockelberg D, et al. Age and acute myeloid leukemia: real world data on decision to treat and outcomes from the Swedish Acute Leukemia Registry. Blood. 2009; 113: 4179-87.

46. Klepin HD, Rao AV, Pardee TS. Acute myeloid leukemia and myelodysplastic syndromes in older adults. J Clin Oncol. 2014; 32: 2541-52.

47. Michelis FV, Messner HA, Atenafu EG, Kim DD, Kuruvilla 
$\mathrm{J}$, Lipton $\mathrm{JH}$, et al. Benefit of allogeneic transplantation in patients age $>/=60$ years with acute myeloid leukemia is limited to those in first complete remission at time of transplant. Biol Blood Marrow Transplant. 2014; 20: 474-9.

48. Rashidi A, Hamadani M, Zhang MJ, Wang HL, Abdel-Azim $\mathrm{H}$, Aljurf $\mathrm{M}$, et al. Outcomes of haploidentical vs matched sibling transplantation for acute myeloid leukemia in first complete remission. Blood Adv. 2019; 3: 1826-36.

49. Sekeres MA, Guyatt G, Abel G, Alibhai S, Altman JK, Buckstein R, et al. American Society of Hematology 2020 guidelines for treating newly diagnosed acute myeloid leukemia in older adults. Blood Adv. 2020; 4: 3528-49.

50. Shimoni A, Labopin M, Savani B, Byrne M, Volin L, Finke $\mathrm{J}$, et al. Comparable Long-Term Outcome after Allogeneic Stem Cell Transplantation from Sibling and Matched Unrelated Donors in Patients with Acute Myeloid Leukemia Older Than 50 Years: A Report on Behalf of the Acute Leukemia Working Party of the European Society for Blood and Marrow Transplantation. Biol Blood Marrow Transplant. 2019; 25: 2251-60.

51. Ustun C, Le-Rademacher J, Wang HL, Othus M, Sun Z, Major $\mathrm{B}$, et al. Allogeneic hematopoietic cell transplantation compared to chemotherapy consolidation in older acute myeloid leukemia (AML) patients 60-75 years in first complete remission (CR1): an alliance (A151509), SWOG, ECOG-ACRIN, and CIBMTR study. Leukemia. 2019; 33: 2599-609.

52. Weisdorf D, Eapen M, Ruggeri A, Zhang MJ, Zhong X, Brunstein $\mathrm{C}$, et al. Alternative donor transplantation for older patients with acute myeloid leukemia in first complete remission: a center for international blood and marrow transplant research-eurocord analysis. Biol Blood Marrow Transplant. 2014; 20: 816-22.

53. Annual Data Summary. Australian Bone Marrow Transplant Recipient Registry. 2019.

54. Heslop HE, Slobod KS, Pule MA, Hale GA, Rousseau A, Smith CA, et al. Long-term outcome of EBV-specific T-cell infusions to prevent or treat EBV-related lymphoproliferative disease in transplant recipients. Blood. 2010; 115: 925-35.

55. Peggs K, Verfuerth S, Pizzey A, Khan N, Guiver M, Moss P, et al. Adoptive cellular therapy for early cytomegalovirus infection after allogeneic stem-cell transplantation with virusspecific T-cell lines. Lancet. 2003; 362: 1375-7.

56. Blyth E, Clancy L, Simms R, Ma CK, Burgess J, Deo S, et al. Donor-derived CMV-specific $\mathrm{T}$ cells reduce the requirement for CMV-directed pharmacotherapy after allogeneic stem cell transplantation. Blood. 2013; 121: 3745-58.

57. Leen AM, Sili U, Vanin EF, Jewell AM, Xie W, Vignali D, et al. Conserved CTL epitopes on the adenovirus hexon protein expand subgroup cross-reactive and subgroup-specific CD8+
T cells. Blood. 2004; 104: 2432-40.

58. Blyth E, Gaundar SS, Clancy L, Simms RM, Bilmon I, Micklethwaite KP, et al. Clinical-grade varicella zoster virusspecific $\mathrm{T}$ cells produced for adoptive immunotherapy in hemopoietic stem cell transplant recipients. Cytotherapy. 2012; 14: 724-32.

59. Blyth E, Clancy L, Simms R, Gaundar S, O'Connell P, Micklethwaite $\mathrm{K}$, et al. BK virus-specific T cells for use in cellular therapy show specificity to multiple antigens and polyfunctional cytokine responses. Transplantation. 2011; 92: 1077-84.

60. Gaundar SS, Blyth E, Clancy L, Simms RM, Ma CK, Gottlieb DJ. In vitro generation of influenza-specific polyfunctional CD4+ $\mathrm{T}$ cells suitable for adoptive immunotherapy. Cytotherapy. 2012; 14: 182-93.

61. Castellano-Gonzalez G, McGuire HM, Luciani F, Clancy LE, Li Z, Avdic S, et al. Rapidly expanded partially HLA DRB1matched fungus-specific $\mathrm{T}$ cells mediate in vitro and in vivo antifungal activity. Blood Adv. 2020; 4: 3443-56.

62. Gottlieb DJ. T time for transplants. Blood. 2010; 116: 43913.

63. Gerdemann U, Katari UL, Papadopoulou A, Keirnan JM, Craddock JA, Liu H, et al. Safety and clinical efficacy of rapidly-generated trivirus-directed $\mathrm{T}$ cells as treatment for adenovirus, EBV, and CMV infections after allogeneic hematopoietic stem cell transplant. Mol Ther. 2013; 21: 2113-21.

64. Leen AM, Bollard CM, Mendizabal AM, Shpall EJ, Szabolcs $\mathrm{P}$, Antin $\mathrm{JH}$, et al. Multicenter study of banked third-party virus-specific $\mathrm{T}$ cells to treat severe viral infections after hematopoietic stem cell transplantation. Blood. 2013; 121: 5113-23.

65. Withers B, Blyth E, Clancy LE, Yong A, Fraser C, Burgess J, et al. Long-term control of recurrent or refractory viral infections after allogeneic HSCT with third-party virus-specific T cells. Blood Adv. 2017; 1: 2193-205.

66. Withers B, Clancy L, Burgess J, Simms R, Brown R, Micklethwaite $\mathrm{K}$, et al. Establishment and Operation of a ThirdParty Virus-Specific T Cell Bank within an Allogeneic Stem Cell Transplant Program. Biol Blood Marrow Transplant. 2018; 24: 2433-42.

67. Bishop DC, Clancy LE, Simms R, Burgess J, Mathew G, Moezzi L, et al. Development of CAR T-cell lymphoma in two of ten patients effectively treated with piggyBac modified CD19 CAR T-cells. Blood. 2021.

https://doi.org/10.31547/bct-2021-014

Copyright (C)2021 Asia-Pacific Blood and Marrow Transplantation Group (APBMT). This is an open access article distributed under CC BY-NC license (https://creativecommon s.org/licenses/by-nc/4.0/). 